\title{
La Sociología Jurídica: construyendo la justicia social*
}

\section{Legal Sociology: Creating Social Justice}

\author{
Luis Alfonso Fajardo Sánchez** \\ Luisa Fernanda García Lozano***
}

Fecha de recepción: 26 de marzo de 2008

Fecha de aprobación: 19 de abril de 2008

\section{Resumen}

El artículo realiza un rápido recorrido por los diferentes momentos en el desarrollo de la sociología jurídica: su historia, fuentes, debates y principales autores. En la breve presentación histórica de esta disciplina, la cual es relativamente nueva en nuestro país, se intenta hacer énfasis en dos pensadores que se han dejado en el olvido después de sus posiciones poco ortodoxas y altamente críticas: Pierre-Joseph Proudhon y Georges Gurvitch, cuyo pensamiento pluralista, la radicalidad de sus ideas, con respecto a la democracia, la justicia y la igualdad, proporcionan elementos para leer la realidad colombiana. Este enfoque permite recrear el desarrollo de la Sociología Jurídica como una fuente para la transformación social.

\section{Palabras clave}

Sociología Jurídica, Sociología del Derecho, pensamiento sociojurídico, historia de la Sociología del Derecho, escuelas críticas del Derecho, Pierre-Joseph Proudhon y Georges Gurvitch.

* El presente artículo constituye un avance de la investigación Jurisprudencia progresista de la Corte Constitucional Colombiana (1991-2000), que adelanta el grupo de investigación Derecho y Sociedad (reconocido por Colciencias en Categoría A en 2006), bajo la coordinación de Luis Alfonso Fajardo Sánchez PhD (Coordinador) y Mg. Luisa Fernanda García Lozano, como investigadora asistente. Los autores expresan su agradecimiento a la socióloga July Samira Fajardo Farfán y a la abogada Carolina Rodríguez Bejarano por sus aportes al presente artículo.

** Doctor en Derecho (Universidad Carlos III de Madrid), Doctor en Sociología del Derecho (Universidad Complutense de Madrid). Director de la Maestría de Derechos Humanos y de la Línea de Investigación Derecho y Sociedad de la Facultad de Derecho de la Universidad Santo Tomás. Correo electrónico: luisfajardo@correo.usta.edu.co

*** Candidata a Magíster en Sociología Jurídica (Instituto Internacional de Sociología Jurídica de Oñati). Docente investigadora de la Facultad de Derecho de la Universidad Santo Tomás y miembro del grupo de investigación Derecho y Sociedad (categoría A de Colciencias). Correo electrónico: luisagarcia@correo.usta.edu.co 


\begin{abstract}
This article proposes an introductory overview of the development of the Sociology of Law: its historical origins, sources, debates and main authors are briefly sketched throughout this dissertation. This insight provides important guidelines to approach this relatively new discipline in our country from two forgotten authors, namely Pierre-Joseph Proudhon and Georges Gurvitch. Their heterodox and contesting viewpoints as well as their pluralist thought, radical ideas on democracy, justice and equality are meaningful elements for analyzing the current state of affairs of Colombian society. Furthermore, this insight provides the framework for understanding the development of the Sociology of Law as a source of social transformation.
\end{abstract}

\title{
Key words
}

Legal sociology, Sociology of Law, Socio-legal thought, history of the Sociology of Law, critical legal schools, authors Pierre' Joseph Proudhon and Georges Gurvitch.

\section{INTRODUCCIÓN}

El presente artículo es un avance de la investigación Jurisprudencia progresista de la Corte Constitucional colombiana (1991-2000), que se viene adelantado en el Grupo de Investigación Derecho y Sociedad del Centro de Investigaciones sociojurídicas Francisco de Vitoria de la Universidad Santo Tomás. El grupo se encuentra actualmente reconocido en categoría A por Colciencias.

El primer trabajo realizado por el grupo se materializó en el libro Los invisibles y la lucha por el Derecho en Colombia. Una mirada desde las Casas de Justicia, en el cual se sentaron algunas bases para la construcción de una metodología de investigación en los estudios de Sociología Jurídica (Fajardo, Abondano \& García, 2006). Los resultados de esta investigación fueron seis protocolos de atención, que estuvieron dirigidos a grupos en condiciones de vulnerabilidad (indígenas, afrodescendientes, población desplazada, adultos mayores, habitantes de calle y trabajadores y trabajadoras sexuales), los cuales se conciben como una posibilidad para la construcción de políticas públicas, a fin de atender los múltiples y graves problemas de estos sectores de la población.

Este avance de investigación corresponde a la primera parte, en la cual se pretende elaborar un panorama general de la teoría de la Sociología Jurídica, en aras de poder identificar los elementos de análisis de la jurisprudencia de la Corte Constitucional, desde este campo de conocimiento. Una de las riquezas de la alianza, no siempre armónica, entre el Derecho y la Sociología se encuentra en la posibilidad de poder estudiar el Derecho desde su ejercicio y desde su impacto en la sociedad. Por lo anterior se encuentran múltiples teorías y debates, que, a través de los años, han facilitado los diferentes desarrollos de esta disciplina y también han permitido que se entiendan las diferentes perspectivas y tendencias que brindan la posibilidad de elaborar categorías para el análisis de los contextos colombianos. Igualmente, es necesario resaltar cómo en este estudio resulta de especial interés identificar la forma en que desde la academia se proponen soluciones reales, posibles, así como deseables, que permitan la solución de los difíciles problemas sociales que vive el país y el mundo en general.

La investigación que se está ejecutando actualmente no se aborda desde la teoría o la interpretación constitucional; el objetivo es seguir avanzando en una metodología de trabajo que dé cuenta del impacto social de esa jurisprudencia. El hecho de enfrentarse a realizar una mirada sociojurídica de la jurisprudencia de la Corte Constitucional colombiana en un periodo de tiempo (1992-2000), el cual 
es calificado por diversos estudiosos del tema como el de "mayor desarrollo de la jurisprudencia progresista en Colombia", genera la necesidad de evidenciar los elementos constitutivos, teóricos, metodológicos, históricos y políticos de la Sociología Jurídica, a fin de que, posteriormente, haya un acercamiento a la jurisprudencia.

El presente artículo se elaboró con el objetivo de que sirva como texto de consulta para el módulo introductorio. Con ello se pretende realizar un aporte a la materia de Sociología Jurídica, puesto que se presenta un análisis del periodo de nacimiento y consolidación de esta disciplina, asimismo, se señalan constantemente las categorías de análisis de sus principales representantes, las cuales permitan una relación con los actuales contextos de Colombia.

\section{EL NACIMIENTO DE UNA NUEVA DISCIPLINA: BREVE RECORRIDO HISTÓRICO}

Para iniciar el recorrido del primer momento de la historia de la Sociología Jurídica, se considera necesario retomar los principales aportes de sus principales representantes en las etapas de nacimiento y consolidación. Para ello se complementaron sus teorías entre sí y a la vez se resaltaron su importancia y sus contribuciones, las cuales permitieron, posteriormente, la creación de nuevas tendencias y escuelas de pensamiento. Las fases propuestas buscan agrupar los autores, en relación con el elemento contemporaneidad y con los aportes conceptuales que permitieron el nacimiento del estudio de la Sociología, entre las cuales se encuentra la fase de iniciadores. En un segundo momento, se encuentran aquellos autores que consolidaron el estudio de la Sociología y que han sido las bases teóricas de los autores contemporáneos y que brindaron los primeros elementos para poder empezar a hablar de Sociología Jurídica como tal. A esto se le denomina fase de consolidación.
En el desarrollo de este artículo es importante destacar a Pierre-Joseph Proudhon y a Georges Gurvitch. Los aportes teóricos de estos autores se consideran fundamentales para entender la problemática desde una perspectiva libertaria; de igual forma, ellos, de una u otra forma, permearon las escuelas críticas desde las perspectivas de pensamiento de varios movimientos y tendencias. Por otra parte, poder llegar a entender y estudiar estos autores permite comprender algunos aspectos sociales de la realidad colombiana, todo esto gracias a la gran riqueza conceptual de sus obras.

\section{El nacimiento}

La fase de los iniciadores está constituida por aqueIlos intelectuales que brindaron las primeras herramientas para el estudio del Derecho y la Sociología desde una perspectiva interdisciplinaria. La base conceptual que proporcionaron estos autores permitió el desarrollo posterior de una Sociología del Derecho, así como el establecimiento de algunos de los elementos que han sido utilizados incluso en nuestros días.

En esta fase se encuentra Auguste François Xavier Comte, sociólogo y discípulo de Saint-Simón. Fue un socialista utópico y fue quien empleó por primera vez el término Sociología en su obra Cours de philosophie positive, la cual fue el resultado de la combinación de un vocablo latino: societas, con el vocablo griego logos. Con este concepto se pretendía definir una nueva ciencia, que descubriera unas leyes para la sociedad, como ya se había hecho con las leyes de la naturaleza, aplicando exactamente los mismos métodos de investigación que eran utilizados en las ciencias físicas. Entre los aportes de Comte se encuentra el hecho de establecer la necesidad de observación objetiva y experimentación en la sociedad.

Para este autor la sociología "fue concebida entonces como el estudio científico de los comporta- 
mientos sociales, dirigidos a proporcionar, a través de la observación, explicaciones nomológicas: es decir, a descubrir en ellos las leyes (en sentido naturalista) que los gobiernan" (Ferrari, 1997, p. 24). Fue así como se expresó la constante preocupación por el estudio de la relación entre la sociedad, la gobernanza y la ley, y cómo se pueden interpretar las manifestaciones de la sociedad. La filosofía, como punto de partida de cualquier ciencia, brinda elementos importantes al estudio de la Sociología Jurídica, pues siempre se preocupó por las formas de manifestación del derecho y el poder, así como por el uso de éstas en la sociedad. Sin embargo, lo hace desde una estructura de pensamiento monolítica y esquemática, a partir de la metodología con las demás ciencias.

La pregunta que intentaba responder Comte, en virtud de la creación de la Sociología, consistía en: ¿cómo establecer los fenómenos sociales y su historia para evitar las formas de revolución incontroladas?, toda vez que en dicha época se señalaba que la crisis provocada por la Revolución Francesa se debía a la ausencia de un sistema universal de principios que permitiera establecer entre las personas la armonía necesaria para cimentar un orden social común, en el cual los individuos pudieran Ilevar a cabo convenientemente sus actividades. De esta forma, la evolución de las ciencias siguió a la evolución de la humanidad. Este pensador

[...] creía en el orden social y en el progreso a través del orden; veía en el individuo y en la exigencia de sus derechos, por ello puso sus acentos en la familia y en la sociedad y en el papel de la mujer dentro de la familia como expresión de los sentimientos nobles de integración, también proclamó la necesidad de una solidaridad entre los individuos que se haría firme con la prestación de los deberes de cada uno a la sociedad (Soriano, 1997, p. 71).

Otro autor importante para la consolidación de la Sociología del Derecho es Carlos Marx (1818-1883), padre del materialismo dialéctico, quien enmarcó su desarrollo teórico en un enfoque histórico estructural que pretende determinar las formas de organización y la dinámica de la sociedad capitalista. Abordó el análisis social a través de la dialéctica, convirtiéndola así en la metodología para el desarrollo de sus escritos y estudios: la realidad social es "como un todo estructurado y dialéctico en el cual puede ser comprendido cualquier hecho, clase de hechos o conjunto de hechos" (Bravo, 1992, p. 50). De igual forma, centró su objeto de estudio en el conflicto-social, más específicamente el producido por clases sociales que están en constante lucha por la dominación del poder desde una perspectiva política y económica.

La crisis que la sociedad del siglo XIX sufrió desencadenó las revoluciones en Europa, la desigualdad y la exclusión, por parte de unos pocos, quienes detentaron el poder y la concentración de la riqueza, lo cual produjo grandes desequilibrios y permitió un análisis, en virtud de las diferencias y la posibilidad de cambio. Marx presupone que "los conceptos y cuerpos teóricos para interpretar la realidad social se pueden transformar porque responden a momentos históricos particulares en el desarrollo de la ciencia, a la vez que se reformulan o abandonan conforme avanza el conocimiento" (Ontiveros \& Mendoza, 1998, p. 35). Por ello analizó los contextos en los que vivía y fijó su análisis en la lógica de la acumulación de la riqueza con las problemáticas que esto acarrea. Con base en ese análisis explicó la existencia de dos clases sociales que, desde entonces, son las protagonistas principales en el desarrollo de los análisis de este autor: el proletariado y la burguesía.

Estas dos clases representan la tensión social de la época de la industrialización, situando en ellos los conflictos sociales de más relevancia: "[...] Sólo el proletariado es una clase verdaderamente revolucionaria. Las demás clases van degenerando y desaparecen con el desarrollo de la gran indus- 
tria" (Marx \& Engles, 1999, p. 35). De tal manera, esta clase social se convirtió en una herramienta de emancipación y control. Sin embargo, la principal dificultad para el fin fue el fenómeno de la alienación en los obreros y en los trabajadores al no tener conciencia del poder que constituye su fuerza de trabajo y la potencialidad de llevar a cabo una revolución desde abajo; la alienación que sufrió esta clase social es producto de una imposibilidad de cambio, que impidió el comienzo de dicha revolución.

También expuso y profundizó la concentración del poder, de la propiedad, la ideología política comunista y la dominación de unos sobre otros; este concepto está representado en "el poder político, hablando propiamente, es la violencia organizada de una clase para la opresión de otra" (Marx \& Engles, 1999, p. 49), el cual se sirve del Derecho para ejercer su fuerza/violencia y para establecer el control de la sociedad, en consecuencia, el Derecho es definido como una superestructura que organiza. En sus obras Marx describió la inconciencia social de las clases en torno a las realidades de cada individuo, los grados de exclusión y división, así como las posibilidades de una trasformación en las estructuras del poder, a través del potencial humano de los individuos que conforman el proletariado y su problemática en el ámbito laboral.

Su perspectiva sociológica y planteamientos sociales se han mantenido en el tiempo; éstos se orientan, en gran medida, a la selección de los antecedentes hecha por diversos autores. Desde la perspectiva de la sociología marxista, en cada sociedad existe una clase económica que domina la estructura productiva, lo que se traduce en supremacía política que se hace extensiva a todas las esferas sociales como, por ejemplo, el derecho, la religión, la cultura, etc. Este dominio es absoluto, ya que a través de la coerción y la imposición ideológica, la clase dominante consigue que la superestructura esté al servicio de sus intereses materiales.
Otra de las tendencias que se gestan en este momento son la antiautoritaria y la anarquista del Derecho, que proveen de elementos importantes, como determinantes, a la consolidación de la Sociología Jurídica, ya que le proporcionan al estudio del Derecho elementos como la conciencia social en torno a la instrumentalización de la fuerza institucional; de igual forma, establece lineamientos referidos a la consolidación de un marco plural de análisis. Su principal representante es PierreJoseph Proudhon (1809-1865), quien propuso una ciencia social que avance del culto a la cultura, de la fuerza al esfuerzo, de la potencia a la capacidad. También intentó probar por esta progresión que la constitución de una ciencia social no es sólo económica, sino que también implica una conciencia social, además de dar relevancia al campo de la justicia y a la defensa por el pluralismo jurídico y sociológico. Los aportes realizados por este autor permiten concebir una propuesta, pues entrega elementos para entender lo que ha sucedido en Colombia desde los años noventa, en especial, cuando se habla de justicia social, motivo por el cual es importante entender a profundidad sus principales postulados.

\section{El Derecho como justicia social: Pierre-Joseph Proudhon}

Entre las principales contribuciones de la fase de los iniciadores, se encuentra la posibilidad de entender el Derecho como una fuente de justicia social, lo que permite verlo como un arma y una posibilidad de equilibrio de las tensiones sociales. Pierre-Joseph Proudhon es su principal representante. El sociólogo Georges Gurvitch Io considera como uno de los padres de la Sociología contemporánea.

La creencia de Proudhon en el desarrollo de las "fuerzas colectivas", le llevó a pensar que sí es posible una sociedad justa y en paz a partir de la solidaridad, el apoyo mutuo y la justicia. Utilizó la noción de sociabilidad de Auguste Comte, en 
la cual se distinguen tres grados: la sociabilidad espontánea, que es afectiva; la sociabilidad, como justicia; $y$, finalmente la sociabilidad, como "igualdad de condiciones que nunca ha sido llevada a la práctica". Las fuerzas colectivas, esas fuerzas que a menudo han definido el destino de nuestro país; por ejemplo, la fuerza que surgió de la rabia -como en la época de la violencia-, del ánimo restaurador -como en el proceso de la Asamblea Nacional Constituyente- 0 de las fuerzas colectivas que avanzan poco a poco hacia el final de la guerra y de la construcción de la paz.

En este sentido el sociólogo francés dice:

¿Qué es lo que hace la realidad del poder social? Es la fuerza colectiva [...]. Los individuos no son los únicos dotados de fuerza; las colectividades también tienen la suya [...] contienen potencia, potencia sintética y consecuentemente especial del grupo, superior en cualidad y en energía, a la suma de las fuerzas elementales que lo componen (Ed. Riviere, De la Justice, Vol. II, 258).

Las fuerzas colectivas en sí mismas no encarnan la justicia, la igualdad, el respeto por la tolerancia, pero pueden generar la conciencia que permita a esa colectividad avanzar en ese sentido. Proudhon no fue ingenuo, puesto que no confió ciegamente en las fuerzas colectivas y por esa razón afirma: "Estas fuerzas colectivas y estos poderes, por intensos que sean, no implican directamente ni justicia, ni derecho, ni ideal; pero pueden engendrarlos y sublimarlos, así como declinar, pervertirse o alienarse".

El autor ve con claridad la importancia que atribuye al Derecho como principio regulador del equilibrio entre las irreductibles antinomias que constituyen toda la realidad social. Distingue entre Sociología general y Sociología del Derecho, la cual pone entre el estudio de las fuerzas materiales y el de la razón colectiva. En su Sociología del Derecho el problema de la tipología jurídica de los grupos es dominante. Según Proudhon, la oposición entre el Estado y sociedad implica oposición entre derecho político y derecho económico. No obstante,

\begin{abstract}
[...] pese a su importante aporte a la sociología del derecho, de su importante idea del pluralismo antinómico de la realidad del derecho y a su creciente relativismo, no pudo librarse de su tendencia a idealizar la sociedad no-estatal y su derecho económico, lo que junto a su racionalismo dogmático no le permitió percibir la variabilidad de las reglas que resuelven los conflictos entre las diferentes clases de derechos (Ed. Riviere, De la Justice, Vol. II, p. 99).
\end{abstract}

Las fuerzas colectivas pueden encarnar la justicia. Se trata de la reglamentación mediante el Derecho, capaz de equilibrar los conflictos tan a menudo engendrados por las fuerzas colectivas. A este respecto Gurvitch afirma:

\begin{abstract}
Proudhon es, ciertamente, excesivamente jurista: en el encabalamiento de la realidad social atribuye un papel demasiado importante al derecho, particularmente al derecho igualitario y mutualista, por una parte, y al derecho social y autónomo preferentemente espontáneo por otra. Los opone al derecho individualista y al derecho estatal surgido del derecho romano tradicional (Gurvitch, 1976).
\end{abstract}

Para ser equitativos con Proudhon y poner de relieve todos sus méritos, tal vez se podría sustituir la palabra "derecho" por las palabras "reglamentaciones sociales" o "control social". Se trata de unos modelos, reglas, signos, señales, símbolos de diferentes clases, que proliferan en toda realidad social. Para que éstos encarnen la justicia, es necesario que el trabajo colectivo de todos genere esos ideales y valores, así como que la razón colectiva logre imponerse. La razón colectiva es el ideal de la justicia, la democracia y la paz, porque es un 
proceso de desalienación de la mente y el cuerpo (Produhon, 2001, p. 34).

Si bien es cierto que a lo largo de su obra La capacidad política de la clase obrera, este autor utiliza varios términos que pudieran ser sinónimos, tales como "conciencia común" o "conciencia social", y que identifica con la "razón colectiva", "el espíritu social" o también con "la razón publica" (Produhon, 2001, pp. 34, 39, 56, 67 y 89), en todas ellas se puede ver su significado como un elemento superior a cada individuo, alejado de intereses personales o individualistas y apostando por el bienestar del colectivo.

Una sociedad de apoyo mutuo o mutualista se inspira en estructuras reales, un principio de transformación sobre las mentalidades, para convertirlas en espíritus conscientes: esta transformación de realidad sociológica en realidad jurídica está incompleta si sus estructuras y mentalidades no están previstas en las relaciones que ellas suscitan: un derecho mutualista se apoya en sus relaciones naturales para transformarlas en relaciones funcionales. El carácter recíproco e igualitario de esa ciencia social no hace más que reflejar la realidad y la autonomía de los órganos que componen la sociedad y la realidad misma. Por lo tanto, el Derecho es igualmente pluralista por su origen sociológico, de lo cual se infiere un pluralismo social basado sobre la competición y la asociación de personas individuales y colectivas. De ello se desprende un pluralismo de hecho, basado en la oposición y en la solidaridad de intereses.

Los anteriores elementos son de la Sociología Jurídica de Proudhon, en la que se refleja que es posible construir en el conflicto, porque la sociedad es una lucha permanente de intereses diversos, pero, aun en estos momentos, las sociedades pueden, mediante las fuerzas sociales, transformar sus ideales en justicia; es precisamente por lo anterior que el sociólogo francés pensaba que el Derecho desempeña un papel importante. El imaginario de justicia se halla en la construcción de "reglamentaciones sociales" y en la "razón social", que no tiene cabida para la injusticia o en el aniquilamiento de la pluralidad. Estos aportes de Proudhon proporcionan elementos para analizar y para explicar por qué en Colombia millones de personas tienen una fe casi ciega en la Constitución Política de 1991 y por qué piensan que la Corte Constitucional, fruto de este proceso, podría llegar a encarnar todos los ideales de justicia y equidad.

\section{FASE DE CONSOLIDACIÓN}

La fase de consolidación o clásica de la Sociología Jurídica se caracteriza por la creación de sus bases conceptuales, que son el punto de partida del desarrollo de las escuelas sociojurídicas. La problemática que se vive en la segunda mitad del siglo XIX y en la primera mitad del siglo XX permitió la creación de aportes conceptuales, en los que intervienen aspectos sociales, políticos y jurídicos, los cuales buscan solucionar aspectos como los desequilibrios estructurales, los cuales, con el tiempo, generan profundas brechas de desigualdad y de exclusión.

Tradicionalmente, en esta fase se destacan los aportes realizados por Emile Durkheim y Max Weber, autores que proporcionaron un aporte fundamental para la Sociología y para el Derecho, puesto que establecieron elementos para las investigaciones interdisciplinarias, en las cuales el objeto de estudio parte de la sociedad en relación con las estructuras y con los controles sociales propios del contexto; a la vez, plantean una metodología que está diseñada de acuerdo con el eje de análisis, el cual, en concordancia con sus estudios, describe los comportamientos colectivos. Cada autor soportó sus teorías a partir de un marco de pensamiento que representa sus tendencias ideológicas, así como sus diferentes bases de formación. 
De igual forma, se encuentran Michael Foucault y Georges Gurvitch, quienes han sido considerados clásicos, ya que, gracias a sus aportes, se consolida el estudio de la Sociología Jurídica, pues brindaron elementos y categorías de análisis, que han sido empleados a lo largo del desarrollo de esta disciplina en la Posmodernidad. Por otra parte, está el filósofo y sociólogo francés Emilio Durkheim, seguidor de la escuela sociológica francesa; fundó sus principios en los avances hechos por A. Comte en relación con la evolución de la sociedad. Entre sus obras más importantes se encuentran El suicidio, La división del trabajo social y Las reglas de la metodología sociológica, esta última fue un gran aporte a la sociología, general, pues encarna la posibilidad de establecer "una delimitación a los campos de la sociología, una metodología para la investigación social y una filosofía de educación para el oficio del sociólogo" (Gene, 2003, p. 173).

De la misma manera, en su afán por separar la Psicología y la Sociología, propuso que el método de investigación de la Sociología fuera el empirismo, método en el cual las hipótesis deben partir de los hechos sociales y su estudio se realiza a través de la práctica. Durkheim reivindicó la aplicación del método científico al estudio de los fenómenos sociales; asimismo, mediante su análisis estableció que éstos son vistos como "cosas" factibles de estudiar objetivamente y provienen de los diferentes contextos externos y coartan el hecho actuar en la sociedad.

Este autor es conocido como un sociólogo organicista, ya que intentó explicar la sociedad como un órgano dentro de un sistema; en sus estudios buscó continuamente la interacción entre la sociedad y sus diferentes relaciones. Durkheim clasificó Ios hechos sociales en dos: materiales e inmateriales; sin embargo, en sus obras se concentró en estudiar los hechos sociales inmateriales, que representan aquellos entes abstractos que rigen la sociedad y que crean constructos sociales. Las categorías propuestas por Durkheim intentan recoger compartimientos colectivos que dan respuesta al porqué de un cuerpo social. Uno de los más importantes fue denominado la conciencia colectiva, que es definido como: "un conjunto de creencias y sentimiento vigentes en el término medio de una sociedad, que influye y coacciona" (Soriano, 1997, p. 93). Sólo a través de la relación y de la creación de estos conceptos sociales macro, el hombre o individuo puede entender la sociedad en las que está viviendo y su funcionamiento.

De igual forma, es necesario establecer que para Durkheim la sociedad existe sólo con base en las relaciones interpersonales de los individuos y en la solidaridad que éstos crean entre sí. Sin embargo, no sólo evidencia dicho elemento como forma de sociabilidad, sino que también existen otros que influyen para entender el funcionamiento de dichas relaciones, por ejemplo, la moral es uno de ellos; ésta la identifica como eje fundante y componente necesario para comprender el funcionamiento de un colectivo: "[...] la moral es el mínimo indispensable, lo estrictamente necesario, el pan cotidiano sin el que las sociedades no pueden vivir [...] la moral nos constriñe a seguir un camino determinado hacia un fin definido [...]" (Durkheim, 1967, p. 70). También estableció que el Derecho es una de las principales manifestaciones de solidaridad, dado que las reproduce y permite su clasificación, dependiendo de sus comportamientos sociales.

El desarrollo del concepto de Derecho, reglas jurídicas, tipos o clases de Derecho, así como su importancia en la sociedad y sus consecuencias por la falta de acatamiento del mismo Durkheim las desarrolla en La división del trabajo social. En este texto argumenta que la única forma para que realmente los derechos sean efectivos es a partir de la conciencia que se tenga de éstas: "en realidad para que los hombres se reconozcan y se garanticen mutuamente los dere- 
chos, es preciso que se quieran, que, por una razón cualquiera, se sientan atraídos unos a otros y a una misma sociedad de que formen parte" (Durkheim, 1967, p. 153). La instauración del Derecho se debe generar desde una producción colectiva, ya que sólo así es posible determinar cuáles son las carencias sociales y así establecerlas conforme a la misma necesidad social.

Asimismo, Durkheim explicó algunas razones del porqué de la desviación jurídica o falta de acatamiento de las normas morales. A dicha condición la denomina "anomia", la cual es producto

[...] de los conflictos que renacen sin cesar y los desórdenes de todas clases cuyo triste espectáculo nos da el mundo económico. Pues como nada contiene a las fuerzas en presencia y no se les asigna límites que estén obligados a respetar, tienden a desenvolverse sin limitación y vienen a chocar unas con otras para rechazarse y reducirse mutuamente (Durkheim, 1967, p. 15).

Este concepto constituye una de las bases de la criminología, puesto que brinda categorías para su análisis. Los aportes de Durkheim en diferentes campos del saber fueron múltiples, sin embargo, la importancia que le otorga a la Sociología proporciona elementos de objetividad para su estudio. La relaciona directamente con la importancia del Derecho en las relaciones sociales para determinar los niveles de solidaridad, al igual que las formas de organización de éstas.

En la historia de la consolidación de la Sociología, otro de los grandes representantes es Max Weber, quien brindó elementos y categorías, constitutivas de la base de la Sociología contemporánea. Sus aportes constituyen uno de los principales ejes para estudiar el Derecho, desde una perspectiva política, y para brindar a las características clásicas de este campo del conocimiento, alcances que hasta el momento no se habían planteado. En sus obras traza una diferencia clara entre ciencias naturales y sociales; de igual forma, muestra la necesidad de diferenciación de los métodos, al tener cada uno un objeto de estudio y características distintas, razón por la cual establece que la unidad de análisis de la Sociología es la acción social, que es acciones mentadas que tienen efectos en la sociedad. Weber es considerado como un sociólogo comprensivo y causalista, es decir, su intención es comprender las situaciones sociales, partiendo de que toda acción tiene una reacción determinada y de esa forma establece el método hermenéutico en sus investigaciones.

La hermenéutica como metodología usa como principal elemento de análisis para entender "la acción social", los tipos ideales, así:

\section{[...] La acción social [...] puede ser com- prendida y explicada a través de las mo- tivaciones que inducen a ella y que es re- conducida a cuatro tipos ideales: la acción racional respecto del fin, que apunta ins- trumentalmente a conseguir finalidades coherentes con los medios que dispone el actor; la acción racional respecto al va- lor, que apunta a la realización de valores o ideales en los que cree el sujeto, inde- pendientemente de las circunstancias materiales; la acción tradicional que el sujeto realiza "por costumbre adquirida" reproduciendo irracionalmente modelos constantemente repetidos; la acción afectiva que el sujeto realiza dando voz a sentimientos o disposiciones de ánimo, siempre de naturaleza predominante- mente irracional (Ferrari, 2006, p. 24).}

De esta manera se representa cómo la exageración de la realidad y los casos tipo generan las bases para comprender posteriormente las posibles consecuencias desde un deber, brindando los dispositivos mínimos que producen un determinado fenómeno, y así lograr explicarlo y analizarlo. El centro de producción de Weber es la política y las esferas de poder, por lo que parte de la legitimidad y la gobernabilidad, aspectos que producen 
un fuerte impacto en la concepción del Derecho en dicha época.

Esta materia es abordada y desarrollada por él desde la Sociología de la dominación, desde la cual la dominación política de tipo legal racional consigue su legitimación precisamente por su sometimiento al ordenamiento jurídico. Weber es caracterizado por sus estudios sobre el ejercicio del poder y sus representantes; en ellos afirmó que, hoy en día, el Derecho se ha convertido en un instrumento de socialización al servicio del Estado.

\section{El Derecho es:}

[...] un complejo de motivos lácticos de determinación de la acción humana real, que está vinculado a los demás órdenes sociales, agrupados por él en los conceptos de utilización, un tanto singular de costumbre. Es derecho vivo en contraste con el derecho jurídicamente válido (Weber, 2001, p. XXV).

Asimismo, este autor comienza a estudiar la validez sociológica, la cual es entendida como:

[...] la oportunidad o probabilidad de observancia de las normas de comportamiento en el caso concreto. No necesariamente equiparable a su cumplimiento efectivo. Por otra parte subraya que a la sociología del derecho no le interesa el desarrollo real de las formulaciones jurídicas (Weber, 2001, p. XXV).

Esta definición brindó las primeras pautas para el debate de la concepción nominal y conceptual de esta disciplina. Al ser éstos los primeros aportes sobre la creación de esta área del conocimiento, era preciso plantear aspectos como la mejor forma de nombrarlo y las consecuencias en los desarrollos, dependiendo de la manera en que se nombrara. De esta forma lo plantea el profesor Leopoldo Múnera:
[...] el debate es planteado por Weber, claramente al afirmar que el mundo de lo jurídico no se reduce al derecho positivo, entonces si uno parte de una concepción no monista del derecho, pues evidentemente habría una diferencia entre sociología del derecho y sociología jurídica, entendida la sociología jurídica como un estudio de las formas jurídicas en la sociedad, más que del derecho positivo, del derecho positivo estatal, y reducía la sociología del derecho a una sociología del derecho positivo estatal. Y Weber lo plantea pues todo el pluralismo jurídico, [...] con una gran claridad, entonces, ahí hay una noción y hay una sociología jurídica, que no es una sociología del derecho, que no hay una preocupación de él por el derecho positivo, sino por las formas de ordenamiento jurídico de la sociedad, que no pasan necesariamente por el derecho positivo estatal (Múnera, 2007).

Hasta nuestros días esa discusión sigue vigente, sin embargo, hace parte de los desarrollos propios de cada línea de pensamiento que se siga al momento de desarrollar un tema. El énfasis e importancia de estos estudios del Derecho, realizados por el sociólogo en mención, provienen de la trasformación del concepto validez, ya que en sus textos puso a prueba su perspectiva dogmática, por lo tanto, las acciones humanas empíricas que tengan una motivación causal y estén orientadas por un orden jurídico que los individuos consideran como válido, corresponden realmente a un comportamiento jurídico en razón del Derecho.

Tal como fue concebida la Sociología Jurídica por Weber, su análisis tomó como punto de partida los múltiples factores que contribuyen a la racionalización del Derecho, la cual es definida como el conjunto interdependiente de fenómenos que permiten ordenar la realidad y comprender el sentido de las acciones humanas. Por otra parte, se encuentra Hans Kelsen, quien fue uno de los mayores críticos de la delimitación del objeto del 
Derecho -planteada anteriormente-, ya que la consideraba restringida, en la medida en que las acciones están orientadas por un ordenamiento jurídico válido, lo cual, en el caso de un hecho antijurídico cometido con pleno desconocimiento de la existencia de la norma, quedaría por fuera de la órbita de la Sociología del Derecho, en los términos propuestos por Weber.

La caracterización de Kelsen como el padre del positivismo jurídico, por su obra Sociedad y naturaleza, se debe a que aborda una perspectiva de estudio sociojurídico de la justicia y entra en diálogo con sus contradictores. Este autor también plantea la importancia de realizar una investigación de la función social para intentar construir el diálogo entre "el deber ser" y el "ser". De esta manera, desde la sociología, expresa: la "sociología dirigida al pensar y actuar 'fácticos' de los hombres, es decir, a una ciencia cuyo exclusivo objeto es la realidad del 'ser', como 'mera ideología'" (Kelsen, 1945 , p. XI).

Asimismo, retomó algunos de los conceptos que desarrollan los sociólogos de la época en el análisis del texto. Sin embargo, este abogado de profesión relaciona la ley natural, la ley moral y la norma social, explicando en su análisis cómo estos tipos de normas no tienen relación con el Derecho:

\begin{abstract}
[...] Para la sociología moderna, un hecho social aparece como parte de la realidad, determinando por las mismas leyes que un hecho natural. No existe diferencia social entre las leyes naturales y las sociales, esto es, entre las leyes que determinan la naturaleza y las que determinan la sociedad, tan pronto como la ley natural misma abandona su pretensión de necesidad absoluta y se satisface con ser una aserción de probabilidad estadística (Kelsen, 1945, p. 410).
\end{abstract}

Para Kelsen la definición del objeto, propuesta por Weber, es válida, en la medida en que el comportamiento humano sea referido al Derecho, mientras éste exista en la conciencia de los hombres como contenido de sus representaciones. Sin embargo, es evidente que para este autor la Sociología sólo es necesaria en una etapa previa de la constitución del Derecho, pues en su aplicación ya no tiene relevancia (Kelsen, 2000).

Otro de los autores de mayor importancia en cuanto al legado para la sociología jurídica es el francés Michael Foucault, quien retomó como eje el concepto poder, para entender las formas de control de la sociedad, a partir de un análisis histórico y de relación acerca de cómo ha sido el establecimiento de las instituciones:

\section{[...] en una sociedad como la nuestra, pero en el fondo en cualquier sociedad, múltiples relaciones de poder atraviesan, caracterizan, constituyen el cuerpo social. Estas relaciones de poder no pueden disociarse ni establecerse, ni funcionar sin una producción, una acumulación, una circulación, funcionamiento de los discursos (Foucault, 1993, p. 8).}

La connotación e importancia del concepto poder, desde una forma de dominación, permea los conceptos de las relaciones sociales, las instituciones y, principalmente, el Derecho, dado que la potestad legítima para el ejercicio de la fuerza y la dominación es dicha institución. Foucault pone en duda la legitimidad de la soberanía de estas relaciones y la veracidad de los discursos de autoridad, desde el medioevo; a través de análisis históricos, demuestra de qué manera la sociedad ha sido creada a partir de discursos y de formas de poder que no representan los intereses de la mayoría cuando busca proteger la legitimidad del poder y la soberanía.

Foucault no delimita el Derecho a una norma o a una regla de comportamiento, cuando se refiere al Derecho como "un conjunto de aparatos, instituciones, reglamentos que aplican el derecho"; de igual forma, define el sistema del Derecho como es el campo judicial: "son los trámites permanen- 
tes de relaciones de dominación y de técnicas de sujeción polimorfas. El derecho es visto, creo, no del lado de una legitimidad a establecer, sino de los procedimientos de sujeción que pone en funcionamiento" (Foucault, 1993, p. 8).

Asimismo, profundiza en temas como el castigo y el poder del Derecho para imponerlo. La justicia y las transformaciones que ha sufrido el Derecho Penal, desde la función de rehabilitar los males de la sociedad; la contención del poder desbordado por la burguesía o el rey es limitado en el establecimiento de un órgano independiente de dicho poder, como es el legislativo; sin embargo, éste sigue siendo manipulado por influencias externas que permiten que el Derecho sea cada vez menos independiente y el ejercicio del poder, dominación e imposición, se realice a través de él.

En sus diversas obras, Foucault explica la relación de verdad, derecho y poder; a cada una le brinda elementos para establecer el funcionamiento en sociedad de las categorías propuestas por él. Aunque estas categorías connoten gran influencia de autores como Marx y no sea contemporáneo con el nacimiento de los sociólogos clásicos, Foucault realiza aportes significativos para el estudio de la Sociología Jurídica y el Derecho, por lo cual en el mundo académico le dan la relevancia como un institucionalizador de esta disciplina.

Igualmente, se encuentra Georges Gurvitch, quien en sus obras proporcionó una de las principales contribuciones en el desarrollo de una pluralidad jurídica y el entendimiento de otras formas de Derecho. También elaboró una de las primordiales teorías de la Sociología Jurídica; sus aportes han sido inspiración de muchos sociólogos de la Posmodernidad; y representa uno de los tantos autores olvidados a través de los tiempos, motivo por el cual a continuación se recuperan algunos de sus postulados, en cuanto es posible relacionarlos con la realidad colombiana.

\section{GEORGES GURVITCH': PRIMER ACERCAMIENTO A LA REALIDAD COLOMBIANA}

Relacionarse con la obra de Georges Gurvitch implica percibir tardía o tempranamente que se está frente a un proyecto sociológico integral, en el cual su labor de investigador y de maestro parece orientada a dotar a la Sociología de un sólido, vasto y complejo aparato teórico y, a su vez, conciliar teoría y práctica.

La obra de Gurvitch ha sido muchas veces incomprendida. En Colombia no son muchos los estudios de Sociología del Derecho que han sido abordados desde este enfoque 0 , por lo menos, los que han citado algunas de las obras de su abundante producción intelectual. El pensamiento plural y la defensa de la diversidad de este autor, la confianza en la solidaridad y el apoyo mutuo, su exagerado optimismo en el Derecho -como forma de resolver los problemas sociales-, la idea de una realidad compleja, pero no incomprensible, su permanente búsqueda de nuevas formas de conciencia social a partir de la multiplicidad de actores sociales, la certeza de que las sociedades son tan dinámicas que no se pueden plantear soluciones perpetuas o transformaciones estáticas, etc., hacen que este estudioso de la relación entre el Derecho y la sociedad tenga una vigencia plena para acercarse a la realidad de nuestro país.

Buscó los elementos sociales que le permiten al hombre ampliar los horizontes de su libertad y la

$1 \quad$ Sociólogo del Derecho nacido en Rusia en 1894. Asistente en Petrogrado (1918), catedrático en Tomsk (1919) y Praga (19211924). Marchó a Francia y se nacionalizó francés en 1928. Dio cursos libres en la Sorbona (1929-1931). Enseñó filosofía en el Collége Sévigné (1932-1934). Se doctoró en Letras en la Sorbona (1932). Profesor suplente en Burdeos; catedrático en Estrasburgo de 1935 a 1948. Durante la guerra, enseñó en varias universidades americanas. Catedrático en la Sorbona (1948). Fundó los Cahiers internationaux de Sociologie. Director de estudios de la École Pratique des Hautes Études; miembro del Comité National de la Recherche Scientifique y de la Presidencia del Centre d'Études Sociologiques; presidente del Institut Fran ais de Sociologie (1953-1955). Murió en 1965. 
paz; éstos son un eje articulador de sus estudios. "Según Gurvitch, la sociedad se halla en permanente estado de revolución debido al dinamismo del hombre y a su aprecio por la libertad. Y ese sentido de la libertad orientó su acción pública" (Gurvitch, 1966). Este aprecio por la libertad lo llevó a tomar posiciones políticas muy radicales, algunas de las cuales casi le cuestan la vida. Para este autor, una de las definiciones que mejor define a la Sociología es: "la ciencia de la libertad y de los obstáculos que ella encuentra".

Entre las obras más destacadas de Gurvitch se encuentra El Derecho Social, estudio sobre esas formas de Derecho que surgen espontáneamente en las sociedades y son independientes del Estado y de su orden jurídico, que pueden tener diversas relaciones con el Derecho estatal, así como con las formas de Derecho, la apuesta por el pluralismo jurídico, su fe en la planeación de formas de Derecho fundadas en la democracia, la propiedad y la propiedad federativa. "Este Derecho no Estatal frecuentemente ignorado por los juristas, que se engendra en cada uno de nosotros, por cada grupo, por cada clase, unas veces de manera espontánea y otras por los precedentes, costumbres, prácticas, etc." (Gurvitch, 1966). Tales elementos pueden servir de insumo para analizar la realidad jurídica en nuestro país, en la cual noventa pueblos indígenas tienen competencia para resolver de manera autónoma sus conflictos, pluralismo ya generoso, más las atribuciones que la Ley 70 de 1993 le otorga a las comunidades negras de administrar justicia de acuerdo con sus tradiciones culturales y, como si fuera poco, la existencia de la institución jurídica de la kriss romaní o justicia de los gitanos. Este panorama se puede leer desde los postulados del Derecho Social de Gurvitch (Fajardo, 2003).

Entre los muchos elementos de la obra de Gurvitch, en relación con la Sociología general, es necesario resaltar al menos dos, por ser los que atraviesan la mayor parte de sus postulados. El primero es su visión de la realidad social como una unidad total y compleja, y que debe ser estudiada de esa manera; el segundo es la utilización del método dialéctico, al que considera "como único adecuado para una sociología que aspire a captar la riqueza de la vida social y a superar algunas limitaciones que arrastra el pensamiento sociológico [...] opción que Gurvitch designa con la expresión hiper-empirismo dialéctico" (Pérez-Agote, 2005, p. 153).

Es vital señalar que la Sociología general no ha sido la única enriquecida con la labor investigativa y teórica de Gurvitch, puesto que parte de sus estudios que fueron enfocados a una de sus ramas especializadas -la Sociología del espíritu humanocomo es el caso de la Sociología del Derecho. Sus investigaciones y conceptualizaciones en esta área conducen al análisis del Derecho como disciplina, de la jurisprudencia como técnica jurídica y de la justicia como uno de los elementos constitutivos de todo Derecho.

La Sociología del espíritu humano, categoría de estudios en la que se encuentra la Sociología del Derecho, tiene una particular importancia en la obra de Gurvitch, "el estudio de la particularización de los valores e ideas espirituales de acuerdo con las estructuras sociales capaces de captarlos y aprehenderlos, define claramente la conformación de la sociología del espíritu" (Gurvitch, 1945, p. 51). Más adelante, en su obra, define las pretensiones de los estudios sobre la Sociología del Espíritu Humano: "es el estudio de los modelos culturales, símbolos sociales, y valores e ideas espirituales colectivos en su relaciones funcionales con estructuras sociales, y situaciones históricas concretas de la sociedad" (Gurvitch, 1945, p. 51).

Este autor identifica como objeto de la Sociología la realidad social, pero a aquella que es considerada en sus distintos niveles de profundidad; estos niveles se interpretan de tal manera que forman un conjunto indisoluble, aludiendo con ello a los fenó- 
menos sociales totales, planteados con anterioridad por Marcel Mauss. En esa realidad social hay:

\begin{abstract}
[...] un ir y venir perpetuo que constituye su propia trama, que va desde la capa superior de la sociedad, pasando por las superestructuras organizadas, por las prácticas cotidianas flexibles, por los modelos técnicos, por los signos y por los símbolos, hasta las conductas derogativas e innovadoras que modifican las prácticas y los modelos, y crean desde los símbolos nuevos, hasta los valores e ideas colectivas, $y$ en fin hasta la mentalidad social, a la vez colectiva e individual (Gurvitch, 1970, p. 12).
\end{abstract}

Dicho autor distingue ocho niveles o planos de profundidad de la realidad social, que se consideran niveles verticales de ésta (Gurvitch, 1945, pp. 47-52):

- En la superficie de la realidad social se encuentran cosas e individuos externamente perceptibles: la base geográfica y demográfica de la sociedad, así como los elementos materiales de ésta (vías, alimentos, etc.); elementos sociales, que están transfigurados por la actividad humana colectiva y por símbolos y valores, atribuidos a ellos por el espíritu colectivo.

- Si se ahonda un poco más en la realidad social, se encuentran organizaciones o más o menos superestructuras, es decir, conductas jerarquizadas y centralizadas de acuerdo con modelos rígidos y reflexivos fijados de antemano.

- Posteriormente está el modelo de clases diversas, de imágenes comunes de conducta colectiva. Estos modelos no necesitan ser rígidos ni fijados de antemano, aparecen en la práctica diaria y se extienden en formas que cambian incesantemente.

- Con base en el plano de las diversas clases de modelos se encuentran las conductas sociales no organizadas. Estas conductas habituales, que tienden a ser prácticas con frecuencia, van más allá de los modelos o los modifican y se oponen a ellos.

- Posteriormente, en un plano más profundo, se encuentra el de los símbolos sociales. Sin éstos ni las organizaciones, ni los modelos, ni las conductas sociales guiadas por tales modelos son posibles. Los símbolos sociales son simultáneamente condicionados por la realidad social y por el espíritu que se realiza en ellos; por ello los símbolos son al mismo tiempo productos y productores de la realidad social y objeto principal del estudio de la sociología del espíritu humano. "Todo modelo cultural, especialmente los que tienen funciones reguladoras y de control, o sea, los que soportan un elemento normativo, están penetrados por sentidos simbólicos que expresan valores espirituales encerrados en hechos sociales" (Gurvitch, 1945, p. 50).

- Con base en el plano de los símbolos sociales, se encuentran las conductas colectivas que innovan, rompen modelos y crean otros nuevos, se hacen especialmente visibles en épocas de efervescencia social. Estas conductas son las menos dependientes de los símbolos.

- En un plano más profundo al de las conductas creadoras, se encuentra el de los valores e ideas colectivas, que actúan como motor inspirador de los símbolos y de las conductas guiadas por éstos. En este plano de la realidad se encuentra la intervención del reino espiritual propiamente dicho, de las ideas y los valores que son heterogéneos e irreductibles a los actos que los realizan y a los estados del espíritu colectivo que los capta.

- Por último se encuentra el plano más profundo de la realidad social, el plano del espíritu colectivo, en el cual los valores e ideas espirituales, particularizados con referencia a épocas y estructuras sociales, deben ser captados, observados y experimentados. Esto supone la existencia de mentalidades colectivas que aspiran hacia tales ideas y valores, que se iluminan por ellos y que son resistidas por ellos. 
El método que encuentra adecuado para el estudio e investigación sobre los niveles de profundidad de la realidad planteados es el sociológico (Gurvitch, 1970, p. 13). Pero no se trata de cualquier método que pretenda serlo, el método que considera sociológico es aquel que toma a la vez todos los niveles de la realidad social y les aplica un punto de vista en conjunto, es decir, un fenómeno social total, pues por más que se estudie de manera específica uno de los niveles, se termina irremediablemente interrelacionando con los demás. Igualmente, aplica al estudio de la realidad social el método tipológico, que se distingue tanto del método que obtiene conclusiones más o menos generales en las ciencias de la naturaleza, como del método que individualiza y particulariza, propio de la historia, de la geografía y de la etnografía, y del método que sistematiza, propio de ciertas ciencias sociales particulares que elaboran sistemas coherentes de modelos, signos y símbolos, que son válidos en un cuadro social concreto.

Este método tipológico, propio de la Sociología, construye tipos sociales discontinuos, pero que se pueden repetir. Generaliza hasta un límite determinado para hacer resaltar más la especificidad del tipo:

Construyendo tipos cualitativamente diferentes, individualiza también hasta un límite determinado, pero a fin de hacer resaltar los cuadros que pueden repetirse. No descuida las sistematizaciones que ofrecen las ciencias sociales particulares, pero sólo para usarlas como puntos de referencias para investigaciones más profundas, destinadas a demostrar cómo todo sistema coherente de modelos y de símbolos es relativo, y depende de un cuadro determinado, o de una determinada situación social (Gurvitch, 1970, p. 13).

Mediante la aplicación de este método se identifican sus dos "tipologías" fundamentales que constituyen, por un lado, el nivel vertical de la realidad social, es decir, los nueve niveles de profundidad y, por otro, los niveles horizontales de ésta o géneros de tipos sociales, de manera que cada elemento del nivel horizontal contiene o puede contener la totalidad de los niveles verticales. Asimismo, identifica tres géneros de tipos sociales (Gurvitch, 1970, p. 16): los tipos de conexiones sociales o formas de sociabilidad, que se actualizan, se combinan, se combaten y equilibran de la manera más diversa, en el seno de cada grupo por pequeño que sea y de cada sociedad global. Toda unidad colectiva real representa un microcosmos de formas de sociabilidad. Las formas de sociabilidad pueden ser designadas con el nombre de tipos microsociológicos y las globales como macrosociológicos.

Como parte de sus investigaciones y planteamientos en Sociología, y como manera de contribuir a su constitución, Gurvitch identifica los que considera los problemas de la Sociología contemporánea, a la cual subdivide en siete ramas, que tienen su originen en lo que él considera los problemas. En esta clasificación se encuentran los problemas de la sociología del espíritu humano, la cual para Gurvitch es la sociología de los signos, las ideas y de los valores, en general. En ella se encuentran la sociología del conocimiento, sociología de la religión, sociología de la moral, sociología del derecho, sociología del arte, sociología del lenguaje, sociología de la educación y, por consiguiente, la sociología de símbolos, ideas y valores.

Como parte del esfuerzo de Gurvitch por consolidar y por distinguir una Sociología del Derecho, en los términos que considera adecuados para ésta, analiza algunos de los componentes propios del Derecho, lo cual representa un intento de realizar la idea de justicia en un medio social dado. Esto se logra:

[...] mediante la regulación multilateral imperativa-atributiva basada en una determinada unión entre pretensiones y deberes; esta regulación deriva su validez de los hechos normativos que dan una garantía social de su efectividad y pueden en ciertos casos ejecutar sus requerimientos mediante la co-acción concreta y 
externa, pero sin que la presupongan necesariamente (Gurvitch, 1970, pp. 65-66).

El autor ubica la justicia dentro del flujo constante de la vida social, en el cual los valores e ideas equivalentes se encuentran en constante conflicto; la vida social se entiende como el equilibrio inestable entre esos valores contrapuestos, impuestos por la relación jurídica. Además plantea que "La justicia junto a los valores jurídicos son los elementos más variables entre todas las manifestaciones del espíritu" (Gurvitch, 1945, p. 60), porque varían simultáneamente en función de variaciones en la experiencia de los valores, diferenciaciones en la experiencia de las ideas lógicas y de las representaciones intelectuales, transiciones en las relaciones recíprocas entre experiencia emocional y experiencia intelectual. Este señalamiento frente al cambio de la justicia es de vital importancia, si se tiene en cuenta que plantea el Derecho como el intento de realización de justicia en un medio social dado.

En el proceso de constitución de la Sociología Jurídica, Gurvitch cree que algunos juristas han opuesto resistencia a su desarrollo, ya que consideran que pone en riesgo el carácter mismo del Derecho. Asimismo, afirma que la resistencia procede, en parte, con una confusión hecha entre el Derecho como disciplina y la jurisprudencia; con respecto a esto plantea que "un elemento constitutivo de todo derecho es un elemento ideal, la justicia y los valores espirituales". En consecuencia, considera la jurisprudencia sólo como una técnica, al servicio especialmente de los tribunales. También agrega, a fin de evitar cualquier futura confusión metodológica, que la jurisprudencia o ciencia jurídica es un arte nada más, sólo sirve para fines prácticos y sólo la Sociología del Derecho y la Filosofía del Derecho pueden ser verdaderas disciplinas teóricas.

\section{CONCLUSIÓN}

La historia de la Sociología Jurídica es el resultado de las tensiones entre dos ciencias autónomas e independientes como son el Derecho y la Sociología, las cuales intentan, desde sus perspectivas, con sus métodos y sus desarrollos, dar respuesta a una parte de los cuestionamientos y problemas de la sociedad, así como de las instituciones jurídicas. Esta área del saber, por su propia esencia interdisciplinaria, tiene grandes potencialidades para analizar desde una mirada plural y crítica la realidad colombiana, dado que su punto de partida, tal como afirma César Rodríguez Garavito, es un

[...] diálogo en donde combina teoría y trabajo empírico. En ese sentido utiliza las herramientas de las ciencias sociales y de la teoría social, para mirar fenómenos jurídicos y que tiene un concepto de derecho más amplio que el que tiene la dogmática jurídica, es decir que considera que el derecho, o sea, es plural y que es en esa pluralidad de manifestaciones del derecho y de funciones del derecho que pueden ser no solamente instrumentales, sino simbólicas, que la Sociología del Derecho entra a estudiar estos fenómenos" (Rodríguez, octubre de 2007).

La naturaleza del contexto colombiano y sus variables de estudio generan la necesidad de identificar diversos elementos y la elaboración de estructuras que permitan comprender la complejidad del país. En virtud de dicho objetivo, es pertinente retomar el estudio de los fundamentos de la Sociología Jurídica, ya que éstos fueron la génesis y la principal fuente de referencia en la producción de tendencias y movimientos de la Sociología Jurídica posmoderna, los cuales son eje de estudio para la construcción de matrices analíticas en esta investigación.

El estudio del Derecho, desde una perspectiva interdisciplinaria, posibilita una ampliación en el campo de estudio y su aplicación. El Derecho necesita una mirada desde la Sociología, así como la Sociología requiere nutrirse de los conocimientos jurídicos para ampliar su capacidad de interpretación, pero, especialmente, de transformación 
de la realidad actual hacia senderos de justicia y equidad, bases que proporcionan los autores anteriormente analizados, al brindar elementos de estudio, cuyos aspectos metodológicos y unidades de análisis abren las posibilidades y los procedimientos en esta área del conocimiento.

En Colombia las corrientes de pensamiento que han desarrollado diferentes aspectos de la sociología jurídica han concebido de una u otra manera esta forma pluralista y crítica de ver el Derecho. Así, movimientos, como el reconocimiento del pluralismo jurídico, han brindado posibilidades a otras temáticas, como son, por ejemplo, las múltiples fuentes de los Derechos Humanos, en las que se considera al mito, la magia y a la misma naturaleza como origen de éstos, respaldando las creencias de los más de noventa pueblos indígenas que habitan la actual Colombia. Dichos estudios constituyen sólo una posibilidad de la aplicación práctica de los postulados teóricos, en este caso de Gurvitch (Fajardo, 1998), con las complejidades de la sociedad.

Finalmente, es necesario evidenciar cómo este artículo obedece a la intención de profundizar en los periodos de gestación de la teoría de la Sociología Jurídica, en los cuales se establecieron los contenidos mínimos de los principales exponentes. Igualmente, se pretende destacar y poner en evidencia la necesidad de crear una metodología de diálogo entre la teoría y la práctica, en especial, en los actuales contextos de nuestro país.

\section{BIBLIOGRAFÍA}

Bravo, Víctor et al. (1992) Teoría y realidad en Durkheim, Marx y Weber. México: Juan Pablos Editores.

Durkheim, Emilio. (1967) La división del trabajo social. Buenos Aires: Shapire.
Fajardo Sánchez, Luis Alfonso. (2002) Las fuentes olvidadas del pluralismo jurídico en Colombia: piratas, negros, indígenas raizales y gitanos. Revista Estudios Socio-jurídicos.

Fajardo Sánchez, Luis Alfonso, Abondano Lozano, Diana Carolina y García Lozano, Luisa Fernanda. (2006) Los invisibles y la lucha por el derecho en Colombia. Una mirada desde las Casas de Justicia. Bogotá: Editorial Universidad Santo Tomás.

Ferrari, Vincenzo. (1997) Acción jurídica y sistema normativo. Introducción a la sociología del derecho. Madrid: Instituto de Derechos Humanos Bartolomé de las Casas, Universidad Carlos III de Madrid.

Foucault, Michael. (1993) Poder, derecho, verdad. Delito y Sociedad -Revista de las Ciencias Sociales, año II (3).

Gene, Mikel. (2003) On Durkheim's Conton Palgrave Macmillan Rules of Sociological Method. London y New York.

Gurvitch, George. (1945) La sociología del derecho. Rosario (Argentina): Editorial Rosario.

Gurvitch, George. (1966) Mi itinerario intelectual o el excluido de la horda. Texto autobiográfico originalmente publicado en Francia, Introducción de Antonio Pérez González.

Gurvitch, George. (1970) La vocación actual de la sociología. México: Fondo de Cultura Económica.

Gurvitch, George. (1976) La Sociología de Proudhon. México: Editorial Antorcha.

Kelsen, Hans. (1945) Sociedad y naturaleza. Una investigación socio jurídica. Buenos Aires: Editorial Desalma. 
Kelsen, Hans. (1991) Teoría pura del derecho. México: Offtset Universal, S.A.

Kelsen, Hans. (1995) Teoría general del derecho y el Estado (Eduardo García Maynez, traductor). México D.F.: Universidad Nacional Autónoma de México.

Marx, Carlos y Engels, Federico. (1999) El manifiesto comunista. Santafé de Bogotá: Editorial Panamericana Ltda.

Ontiveros Delgado, María Teresa y Mendoza Castro, María Eugenia. (1998) Sociología y su contenido histórico. México D.F.: Colegio de Bachilleres.

Pérez-Agote, José María. (2005) La sociología en el Leteo: el largo adiós a Georges Gurvitch. Política y Sociedad, 42 (2).
Proudhon, Pierre Joseph. (2001) La capacidad política de la clase obrera. Madrid: Fundación de Estudios Libertarios "Anselmo Lorenzo".

Raz, Joseph, Alexy, Robert y Bullygin, E. (2007) Una discusión sobre la teoría del derecho. Madrid: Marcial Pons-Ediciones Jurídicas y Sociales, S.A.

Roma Vera, Ángela. (1945) Prefacio. En George Gurvitch. La sociología del derecho (p. XVII. Rosario (Argentina): Editorial Rosario.

Soriano, Ramón. (1997) Sociología del derecho (1 a edición). Barcelona (España): Editorial Ariel S.A.

Weber, Max. (2001) Sociología del derecho. Editorial Menares. 